\title{
Immune Responses during Human Schistosomiasis mansoni
}

\author{
Evidence for Antiidiotypic T Lymphocyte Responsiveness
}

M. S. Lima, G. Gazzinelli, E. Nascimento, J. Carvalho Parra, M. A. Montesano, and D. G. Colley

Centro de Pesquisas Rene Rachou Fiocruz, Universidade Federal de Minas Gerias, 30,190 Belo Horizonte; Minas Gerais, Brazil

Universidade Federal de Juiz de Fora, 31,000 Juiz de Fora, Minas Gerais, Brazil; and the Veterans Administration Medical Center and

Vanderbilt University School of Medicine, Nashville, Tennessee 37203

\begin{abstract}
We present a method for the examination of antiidiotypic cellmediated reactivity during chronic human infections. Pooled and individual sera from patients with schistosomiasis mansoni were purified on immunoaffinity columns of schistosomal egg antigens (SEA). The eluates contained anti-SEA antibodies, but not SEA. These antibody preparations, and their $\mathrm{F}\left(\mathrm{ab}^{\prime}\right)_{2}$ fragments, stimulated dose-dependent proliferation of peripheral blood mononuclear cells (PBMN) and T lymphocytes from some, but not all active or former schistosomiasis mansoni patients, and could do so autologously. Stimulation required presentation by plasticadherent cells. The eluates did not stimulate PBMN from persons who had never had schistosomiasis. Affinity-purified anti-SEA antibodies from former patients (cured for $>10 \mathrm{yr}$ ) did not stimulate PBMN from patients with active infections. Reabsorption on SEA columns removed stimulatory activity from the eluates. We propose that multiclonal, SEA-related idiotypes expressed by some anti-SEA antibodies stimulate proliferation of $T$ lymphocytes that express antiidiotypic specificities.
\end{abstract}

\section{Introduction}

Idiotypic/antiidiotypic (Id/anti-Id) ${ }^{1}$ networks are prominent in current theories of maintenance and regulation of immune responses (1-3). In situations of chronic antigenic stimulation, such as infections like schistosomiasis, Id/anti-Id networks might develop and influence ongoing immune responses and the outcome of the infection.

We sought to develop a system to evaluate patient cellular reactivity against potential idiotypes expressed by antibodies against soluble schistosomal egg antigens (SEA) (4) that develop during human Schistosoma mansoni infections. Not knowing, a priori, which of the many idiotypes that must be expressed in this system were critical, we chose to begin by studying them collectively. Herein we present evidence that immunoaffinity-

Address correspondence to Dr. Colley, Room F324, ACRE Building, Veterans Administration Medical Center, Nashville, TN 37203. 1986.

Received for publication 31 March 1986 and in revised form 30 May

1. Abbreviations used in this paper: A, cells that adhere to plastic; C, controls; E, experimental; ELISA, enzyme-linked immunoabsorbent assay; Id/anti-Id, idiotypic/antiidiotypic; NA, cells that do not adhere to plastic; PBMN, peripheral blood mononuclear cells; SDS-PAGE, sodium dodecyl sulfate-polyacrylamide gel electrophoresis; SEA, soluble schistosomal egg antigenic preparation.

J. Clin. Invest.

(c) The American Society for Clinical Investigation, Inc.

0021-9738/86/10/0983/06 $\$ 1.00$

Volume 78, October 1986, 983-988 purified anti-SEA antibodies can stimulate proliferation of $\mathrm{T}$ lymphocytes from active and former schistosomiasis patients.

We contend that the most likely explanation of this stimulation is that the idiotypes expressed on these anti-SEA antibodies are acting as immunogens to stimulate antiidiotypic $T$ lymphocytes that develop during the course of the infection. We propose that this system demonstrates auto-antiidiotypic cellular responsiveness during this chronic infection. Continued definition of the predominant stimuli and the potential effector functions of the antiidiotypic cells that respond may further the understanding of protective and pathogenic immune responses, and their regulation $(5,6)$, during schistosomiasis.

\section{Methods}

Study populations. Patients with active infections had $S$. mansoni eggs in their feces (7). Former schistosomal patients were those who had repeated negative fecal examinations and a positive history of shedding $S$. mansoni eggs, and had been treated with schistosomicidal drugs 7-35 yr earlier. Control subjects had no eggs in their stools and were from areas in which schistosomiasis was not endemic. Informed consent was obtained before the inclusion of each subject in the study. Patients with active infections were offered appropriate chemotherapy.

Immunoaffinity chromatography. Soluble SEA preparation $(4,8)$ was coupled to CNBr-activated Sepharose 4B (Sigma Chemical Co., St. Louis, MO) (9), and used to affinity purify multiclonal anti-SEA antibodies from pooled or individual sera (9). Eluates obtained by use of $0.1 \mathrm{M}$ glycine- $\mathrm{HCl}$ ( $\mathrm{pH} 2.8$ ) were neutralized with $0.1 \mathrm{M} \mathrm{NaOH}$, dialyzed against $0.05 \mathrm{M}$ ammonium bicarbonate, lyophilized, redissolved in phosphatebuffered saline; sterilized by filtration, and their protein content determined (10).

Characterization of the anti-SEA eluates. Samples of the eluates, standards, or SEA were diluted in sodium dodecyl sulfate (SDS) sample buffer containing $2 \%$ wt/vol SDS, $2 \%$ vol/vol 2-mercaptoethanol, $10 \%$ $\mathrm{vol} / \mathrm{vol}$ glycerol, and $0.01 \%$ Bromophenol Blue in $0.125 \mathrm{M}$ Tris- $\mathrm{HCl}$ buffer, $\mathrm{pH} 6.8$, heated at $95^{\circ} \mathrm{C}$ for $5 \mathrm{~min}$, and analyzed by SDS-polyacrylamide gel electrophoresis (PAGE) (11) in 10\% polyacrylamide gels. Proteins were detected by silver staining (12).

Pooled eluate E was digested with immobilized pepsin (Pierce Chemical Co., Rockford IL). The eluate was dialyzed into $20 \mathrm{mM}$ sodium acetate buffer, $\mathrm{pH} 4.5$, and mixed for $4 \mathrm{~h}$ at $37^{\circ} \mathrm{C}$ with the enzyme. The reaction was stopped by the addition of $10 \mathrm{mM}$ Tris- $\mathrm{HCl}, \mathrm{pH} 7.5$, and centrifuged. The supernatant digest was separated over a molecular sieve column (Ultrogel AcA 34; LKB Instruments, Inc., Gaithersburg, MD), absorbance monitored, and the $\mathrm{F}\left(\mathrm{ab}^{\prime}\right)_{2}$ peak (approximate molecular weight, 100,000 ) pooled, dialyzed, lyophilized, reconstituted, and subsequently added to peripheral blood mononuclear cells (PBMN) cultures.

Enzyme-linked immunoabsorbant assay (ELISA) or anti-SEA antibody activity. The ELISA test used to detect anti-SEA antibody activity in sera and immunoaffinity-purified multiclonal eluates has previously been described in detail (13). Briefly, SEA was adsorbed on flat-bottom microtiter plates (Dynatech Laboratories, Inc., Alexandria, VA) and incubated with serial dilutions of sera or eluates. Bound Ig was detected using the peroxidase-conjugated IgG fraction of polyclonal goat antihuman Ig (Cappel Laboratories, Cochranville, PA), the addition of sub- 
strate and development, and reading of the subsequent color reaction at $490 \mathrm{~nm}$. Linear regression analysis was done for each sample.

Reabsorptions of eluates on SEA-Sepharose. Immunoaffinity purified anti-SEA antibodies ( $42 \mu \mathrm{g}$ protein $/ 0.7 \mathrm{ml}$ ) were reabsorbed on SEASepharose $(0.3 \mathrm{ml})$ or exposed to ethanolamine-blocked Sepharose $(0.3$ $\mathrm{ml}$ ). The mixtures were rotated $18 \mathrm{~h} / 4^{\circ} \mathrm{C}$, centrifuged at $10,000 \mathrm{~g}$ for $30 \mathrm{~min}$ and the supernatant fluids saved and tested directly in proliferative assays.

Cell preparations. PBMN were isolated by Ficoll-diatrizoate density gradient centrifugation (LSM; Organon-Teknika, Charleston, SC) as previously described (13). Plastic-adherent (A) and nonadherent (NA) cells were obtained from $\mathrm{PBMN}$ by a $1 \mathrm{~h} / 37^{\circ} \mathrm{C}$ incubation in plastic tissue culture dishes $(60 \mathrm{~mm}$; Falcon Labware, Oxnard, CA) in $90 \%$ RPMI 1640 (Gibco, Grand Island, NY) and 10\% heat-inactivated fetal calf serum. NA cells were removed and A cells were detached, after 30 min on ice in RPMI 1640, by vigorous pipetting.

$T$ lymphocyte-enriched and B lymphocyte-enriched populations were prepared by anti-Ig panning procedures $(14,15)$. Poly-L-lysine-treated $\left(1 \mathrm{~h}\right.$ at $25^{\circ} \mathrm{C} / 100 \mu \mathrm{g}$ per $\mathrm{ml}$ ) tissue culture dishes were washed and coated overnight at $4^{\circ} \mathrm{C}$ with a mixture of goat immunoaffinity-purified antibodies against human IgG, IgM, and human immunoglobulin mu heavy chain (Jackson ImmunoResearch Laboratories, Inc., Avondale, PA). The antibody solutions contained $80-300 \mu \mathrm{g} / \mathrm{ml}$ of the anti-IgG/IgM, and $150-200 \mu \mathrm{g} / \mathrm{ml}$ of the anti-mu, in $0.05 \mathrm{M}$ Tris- $\mathrm{HCl}, \mathrm{pH} 9.5$. The plates were washed successively with cold phosphate-buffered saline, $\mathrm{pH} 7.4$, containing $5 \%$ and then $0.25 \%$ bovine serum albumin. NA cells were incubated on these plates in $2.5-\mathrm{ml}$ volumes at $25^{\circ} \mathrm{C}$ for $30 \mathrm{~min}$, gently swirled, and reincubated for another $30 \mathrm{~min}$. Unbound cells were collected as the B-depleted, $\mathrm{T}$ cell-enriched populations. The dishes were reincubated with RPMI 1640 with $25 \%$ normal human $A B+$ serum ( 30 min at $37^{\circ} \mathrm{C}$ ), and washed vigorously to obtain the $B$ cell-enriched population.

Immunofluorescence. Indirect immunofluorescence analysis of $\mathrm{T}$ cells used monoclonal anti-T3 (hybridoma cell line \#CRL-8001; American Type Culture Collection, Rockville, MD). Monocytes and macrophages were identified with monoclonal B52.1.1 (kindly provided by Dr. G. Trinchieri, Wistar Institute, Philadelphia, PA). The second antibody was immunoaffinity purified, fluorescein-conjugated, $F\left(a^{\prime}\right)_{2}$ goat anti-mouse IgG (Jackson ImmunoResearch Laboratories). Surface membrane human IgM mu-chain-positive cells were detected by direct immunofluorescence using immunoaffinity purified, fluorescein-conjugated $\mathrm{F}\left(\mathrm{ab}^{\prime}\right)_{2}$ goat antihuman mu-chain (Jackson ImmunoResearch Laboratories).

Cell proliferation assays. Proliferative responses were assayed in triplicate cultures of $200 \mu \mathrm{l}$ containing $1.5 \times 10^{5} \mathrm{PBMN}$ or purified populations of cells. When A cells were added they were included at $2.5 \times 10^{4}$ per culture. Culture medium consisted of $90.4 \%$ RPMI $1640,1.6 \% \mathrm{~L}-$ glutamine, 3\% antibiotic-antimycotic (stock of 10,000 U penicillin, 10,000 $\mu \mathrm{g}$ streptomycin, $5 \mu \mathrm{g}$ Fungizone $/ \mathrm{ml}$; Gibco) and $5 \% \mathrm{AB}+$, heat-inactivated normal human serum. Cultures were in flat-bottom microwell tissue culture plates, maintained at $37^{\circ} \mathrm{C}$ in $5 \% \mathrm{CO}_{2}$ in air for $4 \mathrm{~d}$. They were exposed to $0.5 \mu \mathrm{Ci} /$ culture of tritiated thymidine (specific activity, $17 \mathrm{Ci} / \mathrm{mM}$; New England Nuclear, Boston, MA) for the last $18 \mathrm{~h}$ of culture, and processed for scintillation counting. Cultures contained either multiclonal anti-SEA antibodies (eluates) or SEA at various concentrations cited (experimentals [E]), or were left unstimulated (controls [C]). Data are expressed as E-C values of triplicate cultures unless otherwise stated. Control culture cpm ranged from 209-1,983. Cultures exposed to SEA were cultured for $6 \mathrm{~d}$ at 300,000 PBMN/culture and exposed to $\left[{ }^{3} \mathrm{H}\right]$ thymidine of $2.0 \mathrm{Ci} / \mathrm{mM}$ specific activity for the last $6 \mathrm{~h}$ of culture (13). Control values for these cultures ranged from 3,691-10,283.

\section{Results}

Immunoaffinity-purified eluates contain Ig heavy and light chains. The silver-stained SDS-PAGE analyses of one pooled chronic eluate (eluate $A$ ), one individual eluate from a chronic patient (eluate 5), and one individual eluate from a former patient (eluate 7) are presented in Fig. 1. The major bands of reduced,

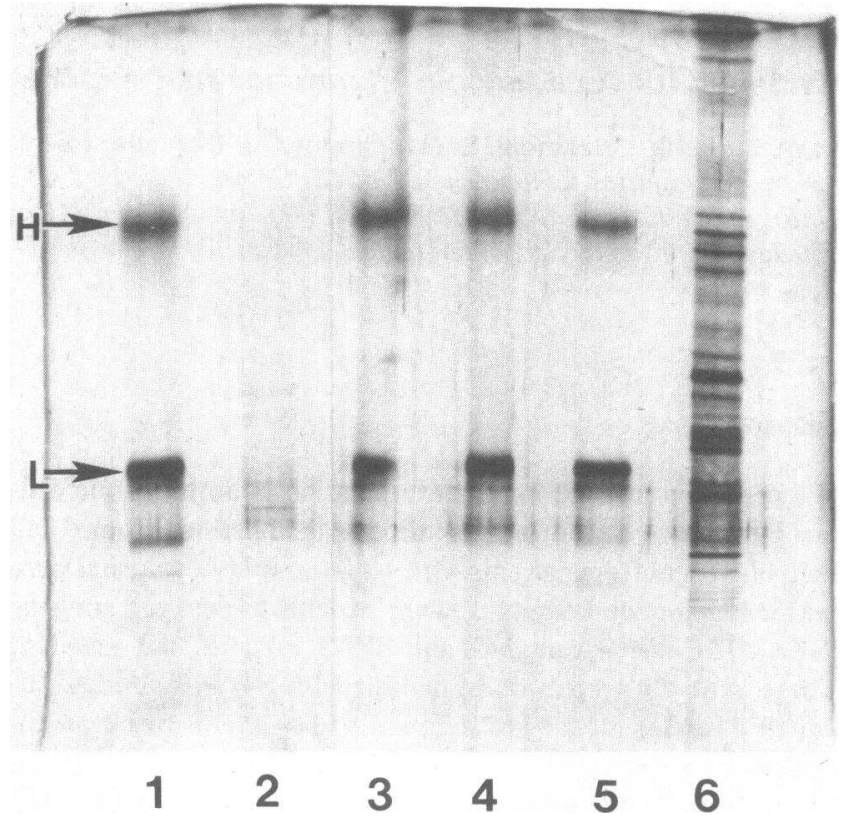

Figure 1. SDS-PAGE analysis of eluates. Lane 1, eluate 7 (15 $\mu \mathrm{g})$; lane 2 , sample buffer; lane 3, eluate A $(12 \mu \mathrm{g})$; lane 4, human IgG standard $(9 \mu \mathrm{g})$; lane 5, eluate $5(10 \mu \mathrm{g})$; lane 6 , SEA $(12 \mu \mathrm{g})$. Arrows and $H$ and $L$ signify the positions of the heavy and light chains of human IgG, respectively.

SDS-denatured eluates were detected in the same positions as those of human IgG heavy and light chains (lane 4, human IgG standard). All lanes contained stained materials found in the sample buffer (lane 2). For comparison, reduced SEA (lane 6) contained multiple components (8), none of which were apparent in the anti-SEA eluate lanes.

Immunoaffinity-purified eluates contain anti-SEA antibody, but not rheumatoid factor. ELISA titers of individual eluates ranged widely in both their anti-SEA $1 / 100$ dilution $\mathrm{A}_{490}$ values and protein concentrations. Pooled eluate $A$ had an absorbance value of 0.555 at $1 / 100$, and an undiluted protein concentration of $1.8 \mathrm{mg} / \mathrm{ml}$. Pooled eluate A was analyzed for its activity in a standard latex agglutination rheumatoid factor assay (16). This multiclonal, anti-SEA eluate was negative in the assay (data not shown).

Patient anti-SEA eluates stimulate PBMN of former patients but not normal subjects. When added to cultures of former patient PBMN, pooled eluate $\mathrm{A}$ from active chronically infected patients stimulated, in a dose-dependent fashion, a strong proliferative response (Fig. 2). The response, as measured by the incorporation of $\left[{ }^{3} \mathrm{H}\right]$ thymidine, was observable by day 3 of culture, but was higher on day 5 . At least $10 \mu \mathrm{g}$ of eluate protein per milliliter of culture was required to stimulate proliferation. Fig. 3 demonstrates that eluate A stimulated the PBMN of another former patient, but did not stimulate the PBMN of a control subject who never had schistosomiasis. Eluates A, 1, 3, and 5 also failed to stimulate the PBMN of any of the five normal individuals tested (data not shown).

Former patient anti-SEA eluates are not stimulatory. Also shown in Fig. 3 is the eluate of a former patient (eluate 7) that did not stimulate those PBMN that were stimulated by eluate A. This was true with several eluates from former patients, i.e., their anti-SEA eluates, prepared on the same SEA immunoaffinity columns and similar in general physicochemical (Fig. 1) 


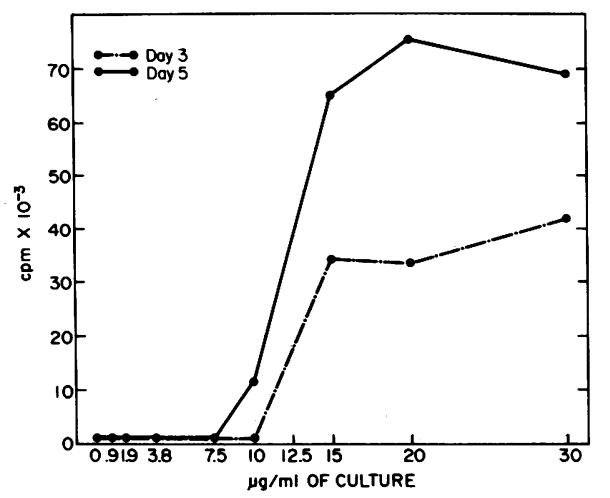

Figure 2. Proliferative responses of PBMN from a former patient exposed to concentrations of pooled eluate $A$ for either 3 or $5 \mathrm{~d}$ of culture.

and immunological (ELISA data) properties, were uniformly nonstimulatory to PBMN from a variety of patients and former patients.

Patient anti-SEA eluates stimulate proliferation of PBMN from some, but not all, patients and former patients. We evaluated the stimulatory ability of numerous anti-SEA eluates (pooled and individual) on PBMN from various patients and former patients. Data from some representative combinations are given in Table I. Pooled eluate A stimulated the PBMN of five of six different former patients. The former patient who was a nonresponder to eluate A responded strongly (over $30,000 \mathrm{cpm}$ ) to individual eluates 3 and 5. Such individual variation was also seen upon assay of the proliferative responses of the PBMN from patients with active infections (Table I). 8 of 13 patients were strong responders to the pooled eluate A. Individual responses to individual eluates from patients with active infections (eluates 1, 3, 4 and 5) were more variable. Eluate 5 was strongly stimulatory to PBMN of only 4 of 13 patients tested. The dose response data presented in Fig. 4 on the effect of eluate $A$ on the PBMN of two chronic patients and one former patient indicate that this variability was not concentration-dependent.

Digestion of a stimulatory pooled eluate by insolublized pepsin, followed by molecular sieve column chromatography, yielded a $F\left(a b^{\prime}\right)_{2}$ preparation. This material was dialyzed, ly-

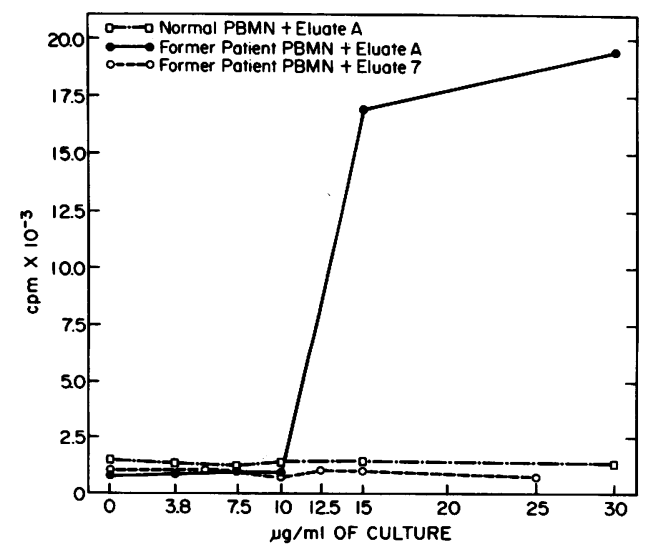

Figure 3. Incorporation of $\left[{ }^{3} \mathrm{H}\right]$ thymidine by $\mathrm{PBMN}$ of a normal (never-infected) subject or a former patient when cultured in concentrations of pooled eluate $A$, and the response of the former patients' PBMN upon exposure to eluate 7 from the serum of a former patient.
Table I. Variability of PBMN Responses to Pooled and Individual Eluates

\begin{tabular}{|c|c|c|c|c|c|}
\hline \multirow[b]{2}{*}{ Patients } & \multicolumn{5}{|l|}{ Eluates* } \\
\hline & $\mathbf{A}$ & 1 & 3 & 4 & 5 \\
\hline \multicolumn{6}{|l|}{ Former } \\
\hline 1 & $++++\ddagger$ & ++++ & ++++ & ++++ & ++++ \\
\hline 2 & +++++ & & & & \\
\hline 3 & +++ & & & & \\
\hline 4 & - & ++ & ++++ & + & $+++t$ \\
\hline 5 & ++++ & & & & \\
\hline 6 & ++++ & - & - & + & - \\
\hline \multicolumn{6}{|l|}{ Active } \\
\hline 1 & ++++ & ++++ & - & - & \\
\hline 2 & $+t$ & $+++t$ & - & & - \\
\hline 3 & $++t+$ & - & ++++ & & + \\
\hline 4 & +++ & - & +++++ & & - \\
\hline 5 & ++++ & + & - & & - \\
\hline 6 & - & $++t+$ & - & & - \\
\hline 7 & - & - & - & & - \\
\hline 8 & + & +++ & ++++ & ++++ & ++++ \\
\hline 9 & ++++ & $+++t$ & ++++ & $++t+$ & ++++ \\
\hline 10 & ++++ & +++ & - & & ++ \\
\hline 11 & $+++t$ & + & ++++ & & ++++ \\
\hline 12 & & - & +++++ & & $+++t$ \\
\hline 13 & & ++++ & ++++ & & - \\
\hline 14 & ++++ & - & - & $\cdot$ & \\
\hline 15 & - & +++ & +++ & & - \\
\hline
\end{tabular}

* Eluate $A$ is from a serum pool from four patients with chronic schistosomiasis mansoni. Eluates 1, 3, 4, and 5 were prepared from the sera of individual patients.

$\ddagger$ Plus ( + ) or minus ( - ) signs are given to equal the following $\mathrm{E}-\mathrm{C}$ values in cpm, $0-1000,-; 1,001-5,000,+; 5,001-15,000$, ++; 15,001$30,000,+++; 30,001-75,000,++++;>75,000,+++++$.

ophilized, and reconstituted, and added to PBMN cultures from six patients and former patients. These anti-SEA $F\left(a b^{\prime}\right)_{2}$ fragments stimulated proliferation in cultures of five of the six individuals tested. The E-C values of these responses ranged from 4,667-35,796.

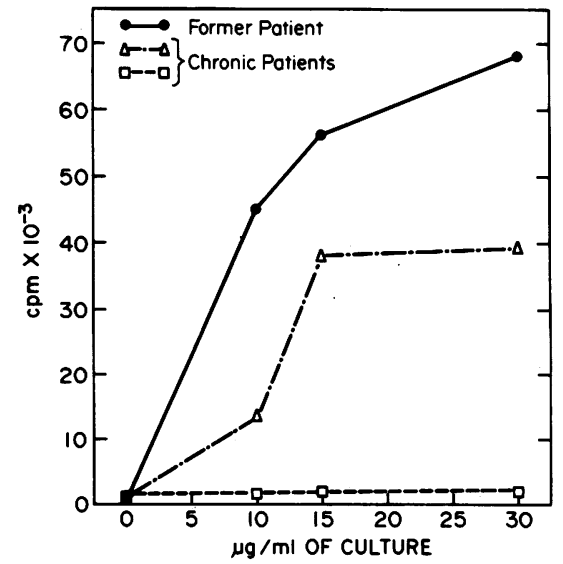

Figure 4. Proliferative responses of PBMN from a former patient, and two patients with the chronic intestinal form of schistosomiasis upon exposure to concentrations of pooled eluate $A$. 
Responses to $S E A$ are independent of responses to individual anti-SEA eluates. It is critical to realize that PBMN from all patients and former patients presented in Table $I$ responded to SEA, but all did not respond to all eluates. A more detailed appraisal of this situation, focusing on active patients $1,2,3,4$, and 6 is presented in Table II. It is clear that while the PBMN of patient No. 1 responded very well to eluates $A$ and 1 , and not to 3, they also responded to SEA. At the same time, and with the same reagents, patient No. 3 responded to eluates $A$ and 3 (eluate 3 being nonstimulatory to patient No. 1) and SEA, and not to eluate 1 . Dose-response curves from more than 100 patients over a 10 -yr period indicate that, in our system, active chronic patients rarely respond to $<10 \mu \mathrm{g}$ SEA protein $/ \mathrm{ml}$ culture fluid (17, 18, Colley, et al. unpublished data).

Reabsorption of eluate A removes stimulatory activity. Stimulatory pooled eluate A was re-exposed to SEA-Sepharose at the same time that it was exposed to ethanolamine-blocked Sepharose, and the resulting supernatant fluids assayed on PBMN of several former patients. Fig. 5 shows that re-exposure of eluate A to insolublized SEA removed, or greatly decreased, stimulatory activity. Anti-SEA antibody levels, as detected by ELISA absorbance at $490 \mathrm{~nm}$, were 0.022 and 0.273 for the SEA-absorbed and ethanolamine-absorbed samples, respectively. Exposure of the eluate to ethanolamine-blocked Sepharose neither removed anti-SEA antibodies, nor decreased the stimulatory property of the eluate.

$T$ lymphocytes respond to anti-SEA eluates in the presence of accessory cells. Separations of PBMN by plastic adherence and anti-Ig panning resulted in an enrichment of T3+ cells from $60-65 \%$ in the PBMN to 82-94\% of the resulting T lymphocyteenriched populations. Surface mu-positive cells in these cell preparations were $<3 \%$, and B52.1.1-positive cells were $<1 \%$ of the total cells. The bound cells recovered from the anti-Ig panning plates were $40-50 \%$ T3-positive and 30-40\% expressed surface mu. The plastic-adherent cell populations (A) were predominantly (50-62\%) large mononuclear cells that bound B52.1.1. Approximately $20-40 \%$ were T3-positive and $<10 \%$ were surface mu-positive.

Fig. 6 presents the data from two separate experiments using cells from two former patients. Their PBMN responded well to chronic eluates, but their $\mathrm{T}$ cell populations did not respond. With the addition of 25,000 A cells to these cultures of 150,000 $\mathrm{T}$ cells, they responded vigorously to the eluates. Neither the $\mathrm{A}$ cells alone $(150,000 /$ culture) nor the B lymphocyte-enriched

Table II. Individual Patient Responses to

Pooled or Individual Eluates or SEA

\begin{tabular}{lcrrr}
\hline & \multicolumn{3}{l}{ Eluates } & \\
\cline { 2 - 4 } Patients & $\mathrm{A}$ & 1 & 3 & \multicolumn{1}{c}{ SEA } \\
\hline 1 & $51,935^{*}$ & 62,479 & -910 & 38,888 \\
2 & 5,184 & 50,518 & 999 & 21,065 \\
3 & 68,209 & 31 & 61,161 & 26,912 \\
4 & 27,004 & 176 & 106,260 & 34,012 \\
6 & 428 & 45,169 & 9 & 55,118 \\
\hline
\end{tabular}

* Responses given in E-C cpm values. Mean control cpm for eluate responses (day 4, 150,000 cells/culture, $954 \pm 186$. Mean control cpm for SEA responses (day 6, 300,000 cells/culture, 7,041 $\pm 1,543$.

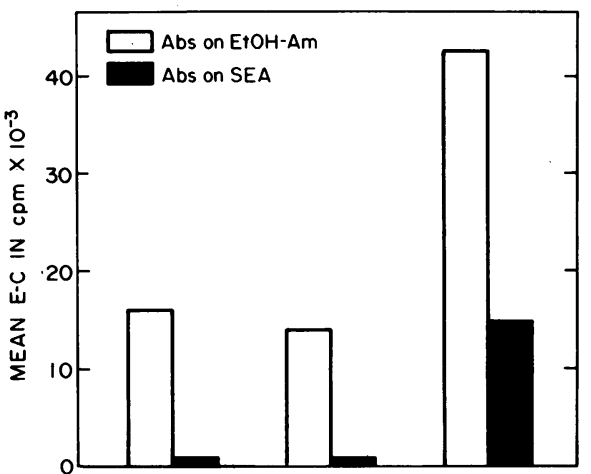

Figure 5. PBMN from three former patients were cultured in the presence of stimulatory concentrations of pooled eluate $A$ after it was reabsorbed on SEA-Sepharose $(\square)$ or Ethanolamine-blocked Sepharose (口). The data indicate the incorporation of $\left[{ }^{3} \mathrm{H}\right] \mathrm{TdR}$ after exposure to these materials.

(T-depleted, macrophage-depleted) populations responded to either eluate.

Adherent accessory cells pulsed with anti-SEA eluates are stimulatory to $T$ lymphocytes. As with an admixture of $\mathrm{A}$ and $T$ cells stimulated by a chronic eluate, if $A$ cells were first pulsed with eluate $A$ for $1 \mathrm{~h}$ at $37^{\circ} \mathrm{C}$, washed, and added to $\mathrm{T}$ cell cultures, stimulation resulted (Fig. 7). In parallel experiments, used as a check on the functional abilities of the separated cells, the addition of A cells pulsed with SEA or monoclonal anti-T3 also induced $\mathrm{T}$ cell proliferation (Fig. 7).

\section{Discussion}

We sought to develop an experimental method to detect cells that were responsive to schistosome-related idiotypes in the PBMN from patients with schistosomiasis. Not knowing which idiotypes and subsequent antiidiotypic responses might play functional roles in antischistosomal resistance or the progress of the disease, we began with an approach that would detect inclusive responses, if they existed, against multiple SEA-related idiotypes. We prepared immunoaffinity-purified anti-SEA antibodies from the sera of patients with schistosomiasis. SEA is an heterogeneous antigenic preparation (8; Fig. 1), and, as revealed by Western blot analysis (Correa-Oliveira, R., unpublished data) both patient sera and anti-SEA eluates recognize multiple SEA components. We reasoned that these anti-SEA antibodies, of multiclonal origin, would express a wide variety of private and potentially cross-reactive idiotypes.

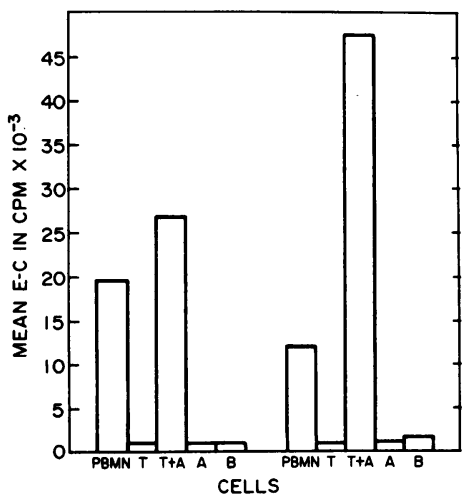

Figure 6. The proliferative responses of PBMN, $T$ cells (T), $\mathrm{T}$ cells + adherent cells $(T+A)$, adherent cells $(A)$, or partially T-depleted, Benriched cells (B) from two former patients, upon exposure to $30 \mu \mathrm{g} / \mathrm{ml}$ eluate $A$. 


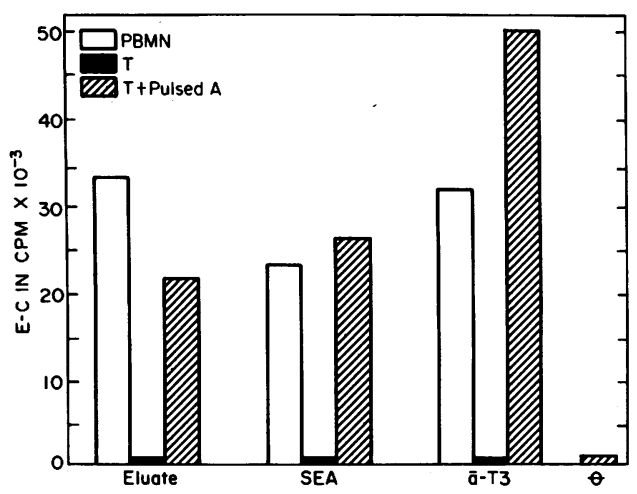

Figure 7. The proliferative responses of PBMN $(\square)$, T cells $(\square)$, or $T$ cells + pulsed adherent cells $(\square)$ from a former patient. Adherent cells $\left(0.5 \times 10^{6}\right.$ in a volume of $\left.0.3 \mathrm{ml}\right)$ were pulsed with either nothing (far right column, $\ominus$ ); $\mu \mathrm{g}$ eluate A; $15 \mu \mathrm{g} \mathrm{SEA}$; or $5 \mu \mathrm{g}$ anti-T3 monoclonal antibody for $1 \mathrm{~h}$ at $37^{\circ} \mathrm{C}$ and added $(25,000$ cells) to $\mathrm{T}$ cell cultures $(150,000$ cells).

We have demonstrated that these preparations, and their $F\left(a b^{\prime}\right)_{2}$ fragments, specifically stimulate $T$ cells in the PBMN of schistosomiasis patients and former patients, and they do so in the manner of an immunogen (19) or anti-T3 (20), i.e., via macrophage presentation. We found no evidence that cellular proliferation was due to direct stimulation of B lymphocytes, either through Fc receptors or membrane-bound Ig molecules. Cell populations moderately enriched for $B$ cells did not respond to anti-SEA eluates, while highly B cell-depleted populations of $T$ cells, upon the addition of low numbers of macrophages, responded well.

Several lines of evidence are presented that indicate that the eluates do not contain SEA, or at least do not contain stimulatory levels of SEA. (a) At the level of protein detection of the silver staining method used (reference $12 ; \sim 5 \mathrm{ng}$ protein) samples of stimulatory eluates containing $10-12 \mu \mathrm{g}$ protein did not contain demonstrable amounts of SEA components. (b) SEA-column passage alone did not yield stimulatory activity: former patients' anti-SEA antibodies were prepared on the same columns and were nonstimulatory (Figs. 1 and 3), and reexposure of stimulatory eluates to the same SEA-columns removed activity as it removed antibody activity (Fig. 5). (c) Individual eluates stimulated the PBMN of certain patients and not others, while SEA stimulated the cells irrespective of their eluate-induced responsiveness (Table II). Together these data imply that eluate stimulatory activity was not due to stimulatory levels of SEA.

The magnitude of the responses engendered by stimulatory, anti-SEA eluates is considerable. These levels can not be compared directly with those stimulated by SEA, because the labeling and culture conditions differed (see Methods). However, data on phytohemagglutinin-P-exposed PBMN, stimulated and labeled in parallel with anti-SEA eluate-exposed cultures, were available on five patients. Phytohemagglutinin-stimulated cultures yielded mean cpm \pm SEM values of $94,262 \pm 13,999$ and the comparable values incorporated by eluate-stimulated cultures was $50,633 \pm 11,888(P<0.05)$. The latter value is substantial, but is clearly not as high as the mitogen responsiveness of these patients' cells under these conditions.

In current studies of other aspects of this system, we have recently observed that an anti-SEA eluate obtained from the serum and tested on the PBMN of the same patient was stimulatory (Novato-Silva, E., D. G. Colley, and G. Gazzinelli, manuscript in preparation). Stimulation in this autologous setting indicates that unusual allotypic interactions are not needed to explain this stimulation. Furthermore, immunoaffinity purified anti-Trypanosoma cruzi antibody eluates from pooled sera from patients with Chagas disease did not stimulate PBMN from former schistosomiasis (non-Chagas disease) patients (Morato, M. J. F., Z. Brenner, and G. Gazzinelli, manuscript in preparation).

We propose that the most likely explanation for the stimulatory nature of the anti-SEA eluates is that the antibodies in these preparations express some idiotypes that collectively stimulate clones of antiidiotypic $\mathrm{T}$ cells in patients and former patients. The sera of former patients, who are not continuously hyperstimulated or well regulated (21) due to their lack of the chronic infection, still contain anti-SEA antibodies. However, the idiotypic representation expressed by these antibodies from former patients may differ, and thus account for the nonstimulatory nature of these eluates.

Schistosomiasis is a chronic infection of some $200,000,000$ people (6). The male and female adult schistosomes live and mate in the vasculature throughout the several years of their life span, and produce hundreds of eggs daily that are released into the blood stream or intestinal wall. The host cell-mediated granulomatous responses against these highly immunogenic, complex eggs are considered to be directly involved in the immunopathology of hepatosplenic disease (6). In experimental and clinical schistosomiasis mansoni it is possible to demonstrate suppressor T cell immunoregulatory control of in vitro (22) and in vivo (23-26) egg-induced granuloma formation. There is evidence that this circuitry can involve antiidiotypic soluble suppressor $\mathrm{T}$ cell factors (27). Furthermore, the development of chronic murine schistosomiasis is correlated with SEA-related antiidiotypic antibody production (9). It would be of interest to evaluate the stimulatory activity of anti-SEA eluates from patients with hepatosplenic schistosomiasis and to determine the responsiveness of PBMN of such patients to their own and others' eluates. With the data base currently available, attempts to correlate a patient's responsiveness, or the lack thereof, with clinical conditions, intensity of infection, or age have been unsuccessful.

In other settings idiotype-related interactions profoundly alter expression of a given host's immunological repertoire (28-30). Perinatal Id/anti-Id interactions can prime for anti-bacterial protection (31), and adult immunizations with antiidiotypes can also lead to antimicrobial resistance (32-34), and antischistosomal resistance (35). A recent report on chronic, experimental murine schistosomiasis japonica (36) has demonstrated crossreactive, immunoregulatory idiotypes that stimulate humoral antiidiotypic responses. The current studies demonstrate the existence of naturally occurring auto-antiidiotypic $T$ cells in human schistosomiasis. Further definition and use of this observation may provide a better understanding of possible roles of Id/antiId reactions in the immunological aspects of resistance and pathogenesis in this infection.

\section{Acknowledgments}

We are grateful to Otavio Francisco Rosa Cruz for his expert technical assistance, and to Dr. Alexander R. Lawton and Dr. Stanford J. Stewart for their critical reviews of the manuscript. We also thank Judith O'Connell for her logistical coordination and secretarial assistance.

This work was supported by grants from the United Nations Development Program, World Health Organization, World Bank, Special Programme for Research and Training in Tropical Diseases, and by the 
Veterans Administration, the Conselho de Desenvolvimento Científico e Tecnológico (Brazil), and the National Institutes of Health (AI-11289).

\section{References}

1. Jerne, N. K. 1974. Towards a network theory of immune response. Ann. Immunol. (Paris). 125:373-389.

2. Paul, W. E., and C. Bona. 1982. Regulatory idiotypes and immune networks: a hypothesis. Immunol. Today. 3:230-234.

3. Kohler, H., J. Urbain, and P. A. Cazenave. 1984. Idiotypy in Biology and Medicine. Academic Press, Inc., New York. 445 pp.

4. Boros, D. L., and K. S. Warren. 1970. Delayed hypersensitivitytype granuloma formation and dermal reaction induced and elicited by a soluble factor isolated from Schistosoma mansoni eggs. J. Exp. Med. 132:488-507.

5. Colley, D. G. 1985. Immune responses and immunoregulation in experimental and clinical schistosomiasis. In Parasitic Diseases, Vol. 1. The Immunology. J. M. Mansfield, editor. Marcel Dekker, Inc., New York. 1-83.

6. Nash, T. E., A. W. Cheever, E. A. Ottesen, and J. A. Cook. 1982. Schistosome infections in humans: perspectives and recent findings. Ann. Intern. Med. 97:740-754.

7. Katz, N., A. Chaves, and J. Pellegrino. 1972. A simple device for quantitative stool thick-smear technique in schistosomiasis mansoni. Rev. Inst. Med. Trop. Sao Paulo. 14:397-400.

8. Carter, C. E., and D. G. Colley. 1978. An electrophoretic analysis of Schistosoma mansoni soluble egg antigenic preparation. J. Parasitol. 64:385-390.

9. Powell, M. R., and D. G. Colley. 1985. Demonstration of splenic auto-anti-idiotypic plaque-forming cells in mice infected with Schistosoma mansoni. J. Immunol. 134:4140-4145.

10. Lowry, O. H., N. J. Rosebrough, A. L. Farr, and R. J. Randall. 1951. Protein measurement with the Folin phenol reagent. J. Biol. Chem. 193:265-275.

11. Laemmli, U. K. 1970. Cleavage of structural assembly of the head of proteins during the bacteriophage T4. Nature (Lond.). 227:680685.

12. Tunon, P., and K.-E. Johansson. 1984. Yet another improved silver staining method for the detection of proteins in polyacrylamide gels. J. Biochem Biophys. Methods. 9:171-179.

13. Gazzinelli, G., J. R. Lambertucci, N. Katz, R. S. Rocha, M. S. Lima, and D. G. Colley. 1985. Immune responses during human schistosomiasis mansoni. XI. Immunological status of patients with acute infections and after treatment. J. Immunol. 135:2121-2127.

14. Reinherz, E. L., A. C. Penta, R. E. Hussey, and S. F. Schlossman. 1981. A rapid method for separating functionally intact human $T$ lymphocytes with monoclonal antibodies. Clin. Immunol. Immunopathol. 21:257-266.

15. Tsoi, M. S., J. Aprile, S. Dobbs, S. Goehle, and R. Sorb. 1982. Enrichment (and depletion) of human suppressor cells with monoclonal antibodies and immunoglobulin-coated plates. J. Immunol. Methods 53: 293-305.

16. Frolich, C. J., and R. C. Williams, Jr., 1980. In Manual of Clinical Immunology 2 nd ed. N. R. Rose and H. Friedman, editors. American Society of Microbiology, Washington, DC 871-872.

17. Colley, D. G., J. A. Cook, G. L. Freeman, Jr., R. K. Bartholomew, and $P$. Jordan. 1977. Immune responses during human schistosomiasis mansoni. I. In vitro lymphocyte blastogenic responses to heterogeneous antigen preparations from schistosome eggs, worms and cercariae. Int. Arch. Allergy Appl. Immunol. 53:420-433.

18. Gazzinelli, G., N. Katz, R. S. Rocha, and D. G. Colley. 1983. Immune responses during human schistosomiasis mansoni. VIII. Dif- ferential in vitro cellular responsiveness to adult worm and schistosomular tegumental preparations. Am. J. Trop. Med. Hyg. 32:326-333.

19. Unanue, E. R. 1984. Antigen-presenting function of the macrophage. Annu. Rev. Immunol. 2:395-428.

20. Van Wauwe, J. P., and J. G. Goossens. 1983. The mitogenic activity of OKT 3 and anti-Leu 4 monoclonal antibodies: a comparative study. Cell. Immunol. 77:23-29.

21. Gazzinelli, G., N. Katz, R. S. Rocha, and D. G. Colley. 1983. Immune responses during human schistosomiasis mansoni. X. Production and standardization of an antigen-induced mitogenic activity by peripheral blood mononuclear cells from treated, but not active cases of schistosomiasis. J. Immunol. 130:2891-2895.

22. Doughty, B. L., E. A. Ottesen, T. E. Nash, and S. M. Phillips. 1984. Delayed hypersensitivity granuloma formation around Schistosoma mansoni eggs in vitro. III. Granuloma formation and modulation in human schistosomiasis mansoni. J. Immunol. 133:993-997.

23. Colley, D. G. 1976. Adoptive suppression of granuloma formation. J. Exp. Med. 143:696-700.

24. Chensue, S. W., and D. L. Boros. 1979. Modulation of granulomatous hypersensitivity. I. characterization of T lymphocytes involved in the adoptive suppression of granuloma formation in Schistosoma mansoni-infected mice. J. Immunol. 123:1409-1414.

25. Green, W. F., and D. G. Colley. 1981. Modulation of Schistosoma mansoni egg-induced granuloma formation: I-J restriction of $\mathrm{T}$ cellmediated suppression in a chronic parasitic infection. Proc. Natl. Acad. Sci. USA. 78:1152-1156.

26. Chensue, S. W., S. R. Wellhausen, and D. L. Boros. 1981. Modulation of granulomatous hypersensitivity. II. Participation of Ly $1+$ and Ly 2+ lymphocytes in the suppression of granuloma formation and lymphokine production in Schistosoma mansoni-infected mice. J. Immunol. 127:363-367.

27. Abe, T. and D. G. Colley. 1984. Modulation of Schistosoma mansoni egg-induced granuloma formation. III. Evidence for an antiidiotypic, I-J positive, I-J restricted, soluble T suppressor factor. J. Immunol. 132:2084-2088.

28. Wikler, M., C. Demeur, G. Dewasme, and J. Urbain. 1980. Immunoregulatory role of maternal idiotypes. Ontogeny of immune networks. J. Exp. Med. 152:1024-1035.

29. Rubenstein, K. J., M. Yeh, and C. A. Bona. 1982. Idiotype-antiidiotype network. II. Activation of silent clones by treatment at birth with idiotypes is associated with the expansion of idiotype-specific helper T cells. J. Exp. Med. 156:506-521.

30. Kresina, T. F., and A. Nisonoff. 1983. Passive transfer of the idiotypically suppressed state by serum from suppressed mice and transfer of suppression from mothers to offspring. J. Exp. Med. 157:15-23.

31. Stein, K. E., and T. Soderstrom. 1984. Neonatal administration of idiotype or antiidiotype primes for protection against Escherichia coli K13 infection in mice. J. Exp. Med. 160:1001-1011.

32. Sacks, D. L., K. M. Esser, and A. Sher. 1981. Immunization of mice against African trypanosomiasis using anti-idiotypic antibodies. $J$. Exp. Med. 155:1108-1119.

33. Sharpe, A. H., G. N. Gaulton, K. K. McDade, B. N. Fields, and M. I. Greene. 1984. Syngeneic monoclonal antiidiotype can incude cellular immunity to reovirus. J. Exp. Med. 160:1195.

34. McNamara, M. K., R. E. Ward, and H. Kohler. 1984. Monoclonal idiotype vaccine against Streptococcus penumoniae infection. Science (Wash. DC). 226:1325-1326.

35. Grzych, J. M., M. Capron, P. H. Lambert, C. Dissous, S. Torres, and A. Capron. 1985. An anti-idiotype vaccine against experimental schistosomiasis. Nature (Lond.). 316:74-76.

36. Olds, G. R., and T. F. Kresina. 1985. Network interactions in Schistosoma japonicum infection. Identification and characterization of a serologically distinct immunoregulatory auto-antiidiotypic antibody population. J. Clin. Invest. 76:2338-2347. 